\title{
Development of Occupational Safety and Health Requirement Management System (OSHREMS) Software Using Adobe Dreamweaver CS5 for Building Construction Project
}

\author{
Nor Haslinda Abas ${ }^{1, *}$, Nurjeha Adman ${ }^{1}$, and Rafikullah Deraman ${ }^{1}$ \\ ${ }^{1}$ Jamilus Research Centre, Universiti Tun Hussein Onn Malaysia, 86400 Parit Raja, Johor, Malaysia
}

\begin{abstract}
The construction industry sector is considered as being risky with frequent and high accident rate. According to Social Security Organization (SOCSO), the construction accidents has arisen from time to time. Construction Industry Development Board (CIDB) has developed the Safety and Health Assessment System in Construction (SHASSIC) for evaluating the performance of a contractor in construction project by setting out the safety and health management and practices, however the requirement checklist provided is not comprehensive. Therefore, this study aims to develop a software system for facilitating $\mathrm{OSH}$ in building construction project, namely OSH requirements management system (OSHREMS), using Adobe Dreamweaver CS5 and Sublime Text as PHP editor. The results from a preliminary study which was conducted through interviews showed that, the respondents were only implementing the basic requirements that comply with legislations, with the absence of appropriate and specific guideline in ensuring occupational safety and health (OSH) at the workplace. The tool will be benefits for contractors and other parties to effectively manage the OSH requirements for their projects based on project details.
\end{abstract}

\section{Introduction}

Malaysian construction industry is one of the largest industries, which has been instrumental in generating wealth in the development of infrastructure and building with social and economic structures through continued growth. However, it is categorized as dangerous working environment due to high accident and fatality rates, as reported in the Social Security Organization (SOCSO) Annual Report [1-3]. The data collected by the Department of Occupational Safety and Health (DOSH) (as shown in Table 1) further indicates that the construction industry had recorded the highest number of fatalities every year. The construction industry contributes more than one-third of fatalities out of all industries and further proves that safety performance in the construction industry lags behind most other industries [4]. These reports provide clear evidence that the industry is

\footnotetext{
*Corresponding author: nhaslin@uthm.edu.my
} 
one of the critical sectors in need of a significant and rapid overhaul to its current site safety practices [5].

Table 1. Percentage ratio of number of fatalities in construction industry to the total fatalities reported to DOSH for the years 2007 until $2016[4,6]$

\begin{tabular}{|c|c|c|c|}
\hline Year & $\begin{array}{c}\text { Number of fatalities } \\
\text { in the construction } \\
\text { industry }\end{array}$ & $\begin{array}{c}\text { Total number of } \\
\text { fatalities reported to } \\
\text { DOSH for the } \\
\text { respective year }\end{array}$ & $\begin{array}{c}\text { Percentage, } \\
\%\end{array}$ \\
\hline 2007 & 95 & 219 & 43.4 \\
\hline 2008 & 72 & 230 & 31.3 \\
\hline 2009 & 62 & 185 & 33.5 \\
\hline 2010 & 63 & 175 & 36 \\
\hline 2011 & 51 & 176 & 29 \\
\hline 2012 & 67 & 191 & 35.1 \\
\hline 2013 & 69 & 185 & 37.3 \\
\hline 2014 (until Nov) & 70 & 184 & 38 \\
\hline 2015 & 88 & 214 & 41.1 \\
\hline 2016 (until Aug) & 55 & 135 & 40.7 \\
\hline
\end{tabular}

It is believed that one of the causes of the increased number of accidents on construction sites is due to the lack of awareness of many parties, particularly employers in providing provisions to ensure safety, health and welfare of the workers. Therefore, it is a responsibility of all parties involved in the construction industry to take preventive action to reduce accidents on the construction site by providing the necessary safety and health of workers at construction site. This study suggests that, one of the ways to avoid accident at construction site is through effective occupational safety and health (OSH) management planning tool. Effective safety can only be achieved when there is a proper management of the interaction between technological systems and people [7]. Even though there are several construction companies has prioritized OSH requirements for their construction projects [8], it is believed that the awareness of contractors (being the management of the project) on OSH management is still lacking [9]. Moreover, it is also believed that many construction companies are not aware of their responsibilities to comply with OSH legislations for effectively managing their construction project.

Realizing the importance of protecting workers from occupational accident and injury, the Government of Malaysia has introduced the necessary legislations related to the industry, in which to be complied by the parties involved in the workplace (including employers and employees). In Malaysia, the main legislations covering health and safety in the workplace are the Occupational Safety and Health Act (OSHA) 1994 [10] and Factory and Machinery Act (FMA) 1967 [11]. The introduction of the comprehensive legislations was in response to the need to cover a more diverse employee base and newer hazards introduced in the workplace [4]. Occupational Safety and Health Act 1194 (Act 514) is the legislations enforced by the Department of Occupational Safety and Health (DOSH) which is a legislative framework in Malaysia construction industry to ensure safety, health and welfare of persons who are at work and to protect other person against safety risk or health in connection with the activities of persons at work. Factory and Machinery Act 1967 (Act 139 ) is to provide for the control of factories with respect to matters relating to safety, health and welfare of persons therein, the registration and inspection of machinery and for matters connected therewith.

At construction site, the contractor is the most responsible party in ensuring safety and health of the workers. One of the ways the contractor can do to address this is through effective occupational safety and health ( $\mathrm{OSH})$ planning tool on a construction site and 
necessary administrative arrangements before the commencement of construction activity. It is essential for contractors to comply with safety and health requirements stipulated in OSHA 1994 and FMA 1967 (including Building Operations and Works of Engineering Construction (BOWEC) 1986 Regulation) in order to minimize the accident happen on construction worksite [11]. Besides that, even though there exists a tool named Safety and Health Assessment System in Construction (SHASSIC) developed by Construction Industry Development Board [12], this tool is only intended for evaluating the performance of a contractor in construction project, by setting out the safety and health management and practices of contractor for various aspects of the construction work activities. SHASSIC provides a valuable checklist for safety and health compliance to the contractors, but the checklist is not comprehensive which covers three (3) aspects only, i.e. document check, site/workplace inspection and employees interview [4]. Moreover, it is also believed that many construction companies are not aware of their responsibilities to comply with OSH legislations for effectively managing their construction.

Therefore, this study seeks to overcome this problem by developing a system tool that can be used by contractors or other parties to effectively manage or plan the OSH requirements for their project, which comply to related OSH legislation.

\section{Development process of the system}

The development process consists of several stages, namely i) preliminary survey; ii) identification and validation of OSH requirements based on OSHA 1994, FMA 1967 and BOWEC 1986for building construction project; and iii) preliminary development of decision support system using Adobe Dreamwaver CS5 software.

\subsection{Preliminary survey}

A preliminary survey was conducted to investigate the issues related to occupational safety and health $(\mathrm{OSH})$ requirements faced by contractors. This task was executed through interviews with five experienced contractors to obtain information about their understandings and implementation of $\mathrm{OSH}$ requirements at the workplace. The respondents were those who are the owners of the companies and also who hold the managerial level of the project.

From the interviews, it is found that all contractors did not have a specific guideline or checklist in implementing the safety and health for effective OSH management and planning tool. Most of them implemented general safety precautions as mentioned in the tender document. Other than that, majority of the repsondents are lack of knowledge regarding the requirements of OSH and FMA in their OSH implementation. This showed that there is a strong need to develop a checklist-based-system tool for OSH requirements that comply with OSH legislations based on project details that could help contractors to facilitate OSH requirements for their project effectively, and further improve safety and health performance at the construction site.

\subsection{Identification and validation of Occupational Safety and Health (OSH) requirements based on OSHA 1994 and FMA 1967}

Next, in order to develop a system of OSH requirements tool for construction projects, in depth study and analysis of the OSH requirements as stipulated in the legislations were executed. The legislations being studied include OSHA 1994, FMA 1967 and BOWEC 1986. The requirements were divided into several categories, which are site management 
(registration); appointment of safety personnel; safety and health committee; documentation; site planning; concrete work; structural steel; catch platforms; chutes, safety belts and net; ladder and step-ladder; scaffolds; excavation work; piling; and machinery. These requirements serve as the basis for information that underpin the development of the OSHREMS.

In order to ensure the validity of the secondary data for developing the system, the OSH requirements identified need to be validated by an expert panel. Validation process was done through a series of interviews with Johor state DOSH officers whom currently incharge in the construction safety department. One of the officers' main responsibilities is conducting site inspection and other various OSH compliance for construction sector. From the validation process, there were several requirements identified that need to be improved in terms of naming or addressing the requirements. Whereas, there were also some requirements found irrelevant and need to be excluded, for example, the requirement for timber scaffold. According to one of the panels, the used of timber scaffold is prohibited at construction site.

\subsection{Preliminary development of OSHREMS using Adobe Dreamweaver CS5}

After obtaining the database of OSH requirements for building construction project, these information were then transferred into a system, using Adobe Dreamweaver CS5 software. Before commencing the development of the system tool, the flow process of the system need to be recognized (as shown in Fig. 1) to facilitate the development process. The OSHREMS commences with the user identification to sign up or sign in to the system, followed by him/her to fill in the project information. Next, the OSHREMS will display the $\mathrm{OSH}$ requirements for the specified project, and the user can opt for printing out the OSH requirements listed.

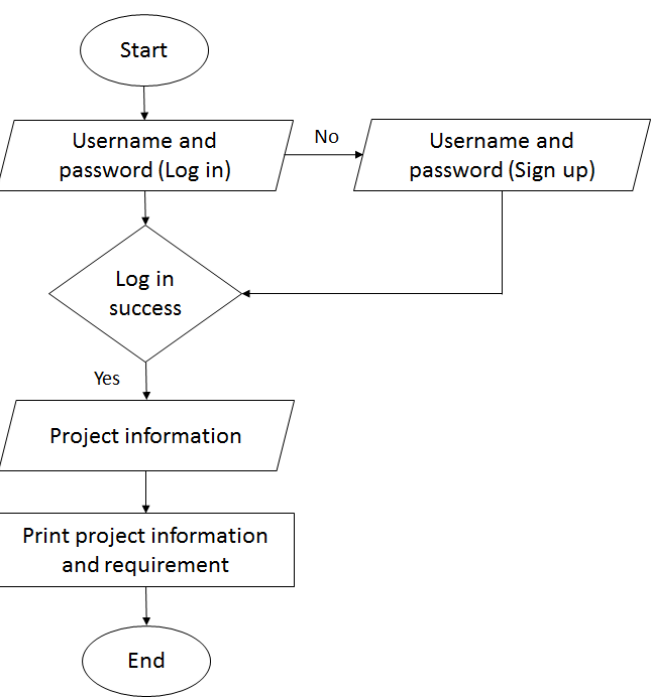

Fig. 1. Flow chart of the system

In developing the OSHREMS, Adobe Dreamweaver was used to create the graphic user interface and to write the codes of the project. The system was operated using MYSQL Server that act as a database, and the system interface was designed using Adobe Dream Weaver CS5 software. This system required some codings to develop the OSH requirement. To develop the interface, some codes for each requirement and interface 
codes were needed to designing the background and produce the project information interface.

Fig. 2 shows the main menu interface of the OSHREMS. In this interface, the user needs to enter their username and password before click Login. The Reset button is used to clear the username and password at once.

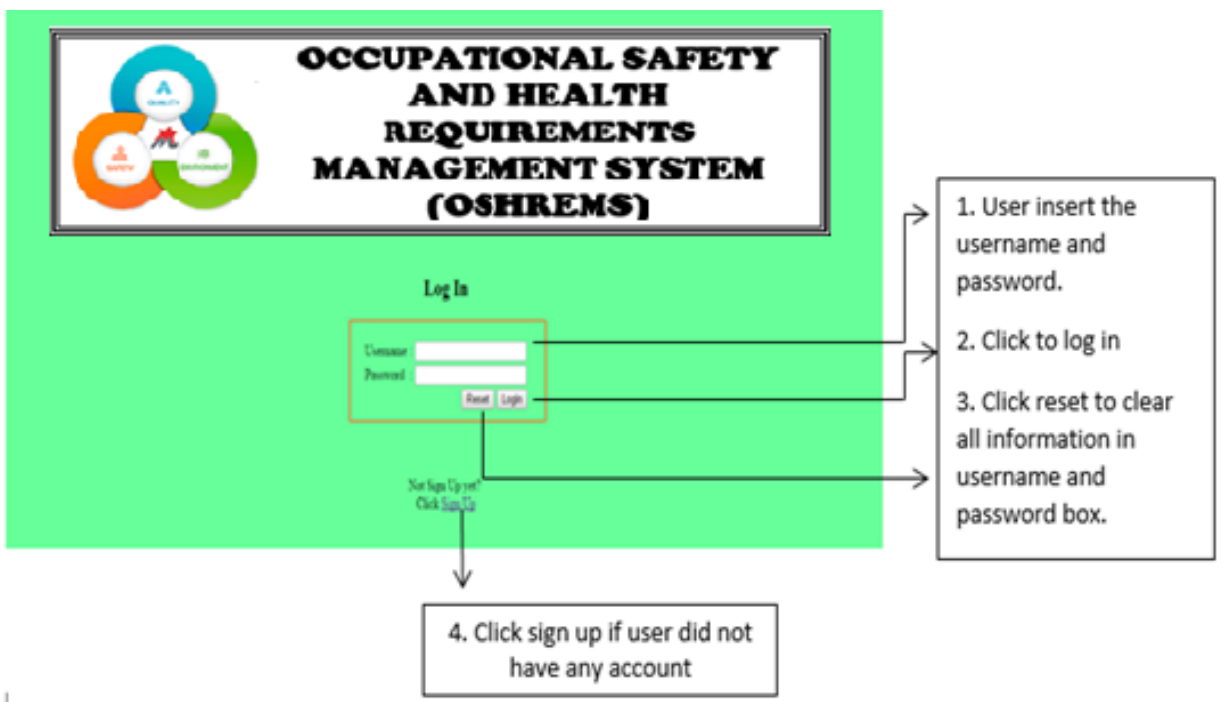

Fig. 2. Main menu interface

Once the user has succesfully logged in to the system, the 'Home interface' will be displayed (Fig. 3). 'Home interface' shows the project information details that the user need to fill. Besides general project information, the user also needs to fill in the information about the plant and scaffolds use (if any) at the construction site. After obtaining the database of OSH requirements for building construction project, based on the information input these information will then be transferred into a system.

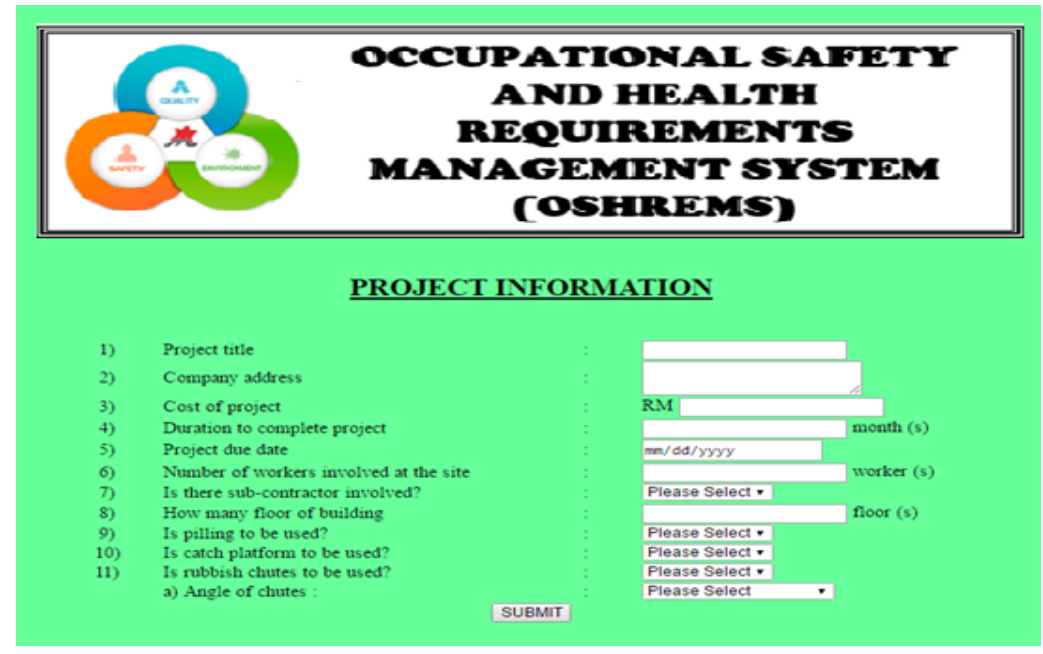

Fig. 3. OSHREMS Home Interface 
Once the information of project are determined, the system will identify the requirements of OSHREMS of the project based on the data input and give the output as shown Fig. 4. The user can opt for print the OSH requirement checklist (based on project details) for their project.

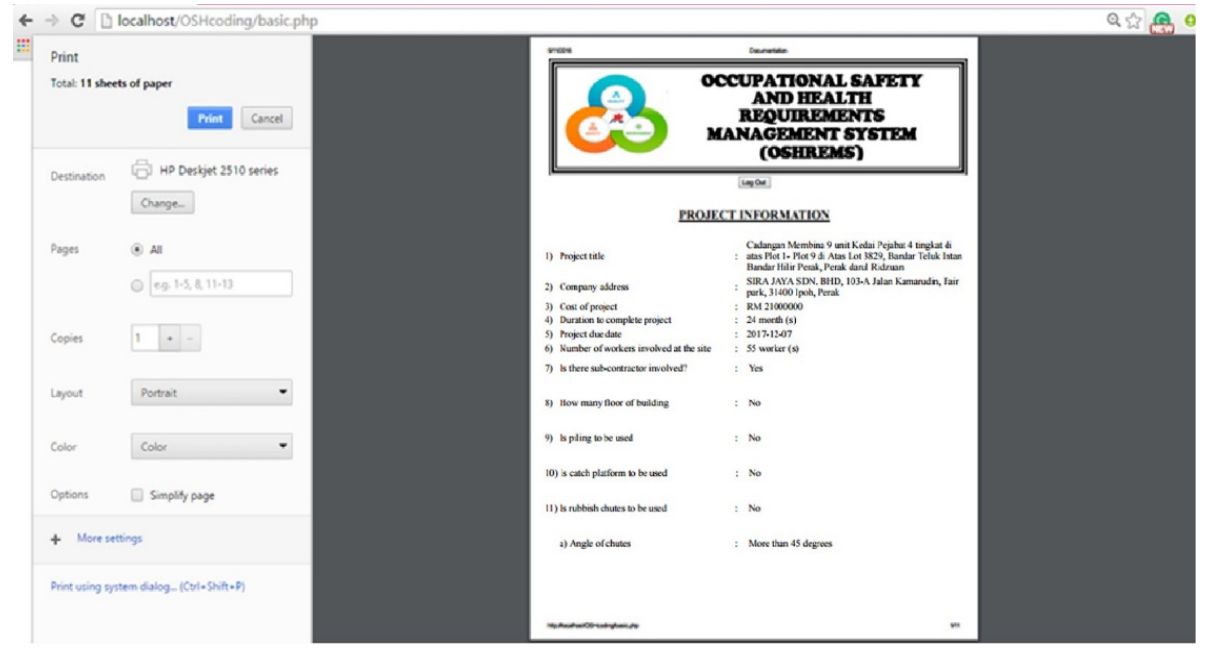

Fig. 4. Example of OSHREMS generated output

\subsection{Evaluation of OSHREMS using existing case study}

Software validation or, more generally, verification and validation $(\mathrm{V} \& \mathrm{~V})$ is intended to show that a system both conforms to its specification and that it meets the real needs of the user of the application [13]. Therefore, in order to ensure the functionality of the developed system, it was tested using a real case study based on the information of one particular building construction project. The project of "Cadangan Membina 9 unit Kedai Pejabat 4 tingkat di atas Plot1 - Plot 9 di Atas Lot 3829, Bandar Teluk Intan Bandar Hilir Perak, Darul Ridzuan" was selected as a case study. Fig. 5 shows the result from the OSHREMS for the 'Project Information' display as keyed in by the user.

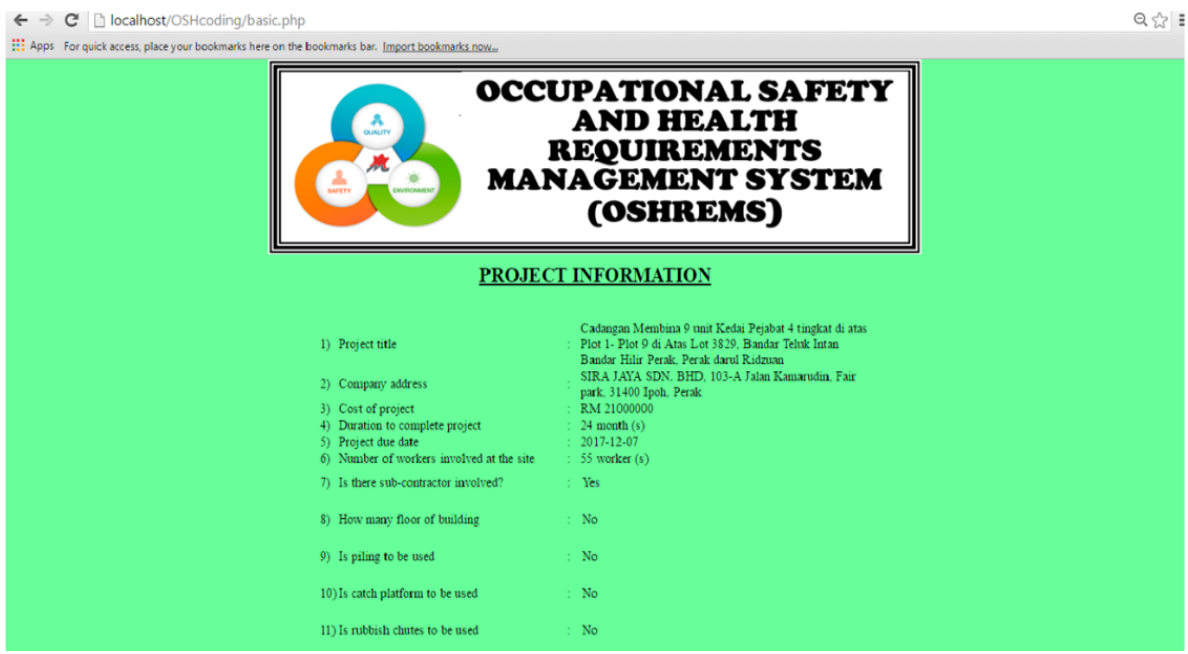

Fig. 5. Example of 'Project Information' display in OSHREMS 
With regards to OSH requirements, Fig. 6 shows the OSHREMS output for 'Appointment of Safety Perdonnel' requirements. The OSH requirements shown are based on the information inserted by the user in the project information interface. For example, since the project is more than RM20 million, the appointment of Safety and Health Officer (SHO) is mandatory as stipulated in OSHA 1994 and Occupational Safety and Health (Safety and Health Officer) Order 1997. Safety and health committee is also need to be established because the project involved more than 40 workers (as stipulated under Section 30(1) of OSHA 1994. It is to be noted that this paper only provides an example of part of the OSH requirements needed for a particular building construction project.

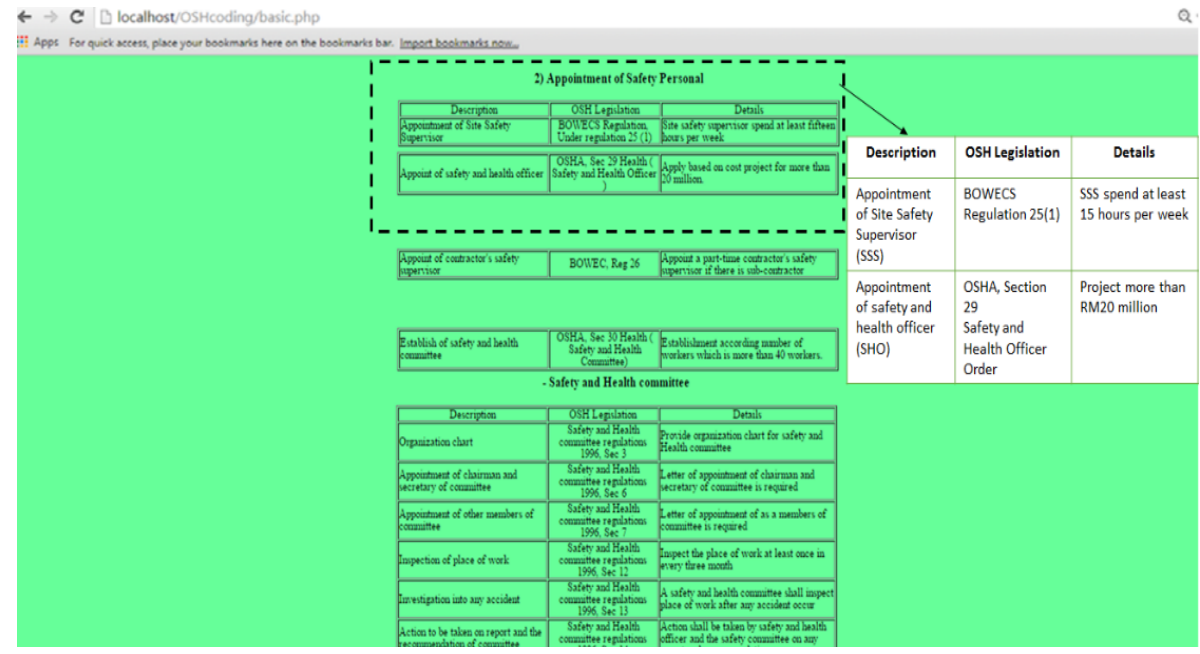

Fig. 6. Example of OSHREMS output for 'Appointment of Safety Personnel' requirement

\section{Conclusion}

The integration of safety knowledge management and information technology can offer an advanced means for improving safety in the Malaysia construction industry. The purpose of this work is to develop the OSHREMS that can be utilized by contractors and other relevant parties (e.g. client, consultant, local authority, etc.) in the building construction project. The proposed system would pave the way to an innovative safety management approach in construction projects, departing from the traditional mode in Malaysian construction industry. This approach would also add value to the current knowledge-based of construction safety management. The authors believe that OSHREMS tool would be able to provide a guideline that can aid the contractor (and/or other relevant parties) of the building construction project about the legislation-based OSH requirements that need to be fulfilled based on their project information and further enhance safety performance by reducing the number of accidents on sites. The OSHREMS tool is also capable to facilitate OSH management planning that benefits all parties, especially during the planning stage, despites encouraging them to fully implement the OSH requirements that comply to legislations and not only implementing minimum safety requirements. Further research is underway to improve the contents available and test the system in large scale case study.

The results presented in this paper are parts of an ongoing research project. This research was supported by Fundamental Research Grant Scheme (FRGS) (Vot 1579). 


\section{References}

[1] C. L. Foo, Budgeting For Occupational Safety And Health Management And Its Implementation, MBAM Annual Safety Conference, (2005)

[2] SOCSO, Annual report for 2000, Social Security Organisation (SOCSO), Kuala Lumpur, Malaysia, (2000)

[3] SOCSO, Annual report for 2000, Social Security Organisation (SOCSO), Kuala Lumpur, Malaysia, (2009)

[4] N.H. Abas, Development of a Knowledge-Based Energy Damage Model for Evaluating Industrialized Building System (IBS) Occupational Health and Safety (OSH) Risk, PhD Thesis, RMIT University, Melbourne, Australia, (2015)

[5] A.R.A. Hamid, M.Z.A. Majid and B. Singh, Causes of Accidents at Construction Sites, Malaysian Journal of Civil Engineering, 20(2), 242-259, (2008)

[6] DOSH, Accident Statistics, Department of Occupational Safety and Health, (2016), Retrieved on October16, 2016 from http://www.dosh.gov.my

[7] I. F. Mohd Kamar, N.S. Lop, N.M. Salleh, S. Mamter, H.A. Suhaimi, Contractor's Awareness on Occupational Safety and Health (OSH) Management Systems in Construction Industry, Emerging Technology for Sustainable Development Congress (ETSDC 2014), EDP Sciences, 1-6, ( 2014)

[8] B. Fernandez-Muniz, J.M. Montes-Peon, and C. J. Vasquez-Ordas, Safety management system: Development and validation of a multidimensional scale, Journal of Loss Prevention in the Process Industries, 20(1), 52-68 (2007)

[9] K. Dorjil, B. H. W. Hadikusumo, Safety Management Practices in the Bhutanese Construction Industr, Journal of Construction in Developing Countries, 11(2), 53-75, (2006)

[10] The Commissioner of Law Revision, Occupational Safety and Health Act 1994, The Commissioner of Law Revision, Malaysia, (2006)

[11] The Commissioner of Law Revision, Factories and Machinery Act 1967, The Commissioner of Law Revision, Malaysia, (2006)

[12]CIDB, Construction Industry Standard (CIS) 10:2008 Safety and Health Assessment System in Construction, Construction Industry Develoment Board (CIDB), Malaysia, (2006)

[13]I. Sommerville, Software engineering $9^{\text {th }}$ Edition, Pearson Education, Massachusetts, USA, (2011) 